\title{
Prehospital Application of the Canadian Triage and Acuity Scale by Emergency Medical Services
}

\author{
Murdoch Leeies, $\mathrm{MD}^{* \dagger *}$; Cheryl ffrench, MD*; Trevor Strome, MSc*; Erin Weldon, $\mathrm{MD}^{* \S}$; \\ Michael Bullard, MD"; Rob Grierson, $\mathrm{MD}^{* \S}$
}

\section{ABSTRACT}

Objectives: Triage is fundamental to emergency patient assessment. Effective triage systems accurately prioritize patients and help predict resource utilization. CTAS is a validated five-level triage score utilized in Emergency Departments (EDs) across Canada and internationally. Historically CTAS has been applied by triage nurses in EDs. Observational evidence suggests that the CTAS might be implemented reliably by paramedics in the prehospital setting. This is the first system-wide assessment of CTAS interrater reliability between paramedics and triage nurses during clinical practice.

Methods: Variables were extracted from hospital and EMS databases. EMS providers determined CTAS on-scene, CTAS pre-transport, and CTAS on-arrival at hospital for each patient ( $N=14,378)$. The hospital arrival EMS CTAS (CTAS arrival) score was compared to the initial nursing CTAS score $\left(\right.$ CTAS $\left._{\text {initial }}\right)$ and the final nursing CTAS score $\left(\right.$ CTAS $\left._{\text {final }}\right)$ incuding nursing overrides. Interrater reliability between ED

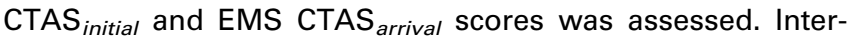
rater reliability between ED CTAS $_{\text {final }}$ and EMS CTAS arrival $_{\text {. }}$ scores, as well as proportion of patient encounters with perfect or near-perfect agreement, were evaluated.

Results: Our primary outcome, interrater reliability [kappa $=$ $0.437(p<0.001,95 \% \mathrm{Cl} 0.421-0.452)]$, indicated moderate agreement. EMS CTAS arrival $_{\text {and ED CTAS }}$ initial scores had an exact or within one point match $84.3 \%$ of the time. The secondary interrater reliability outcome between hospital

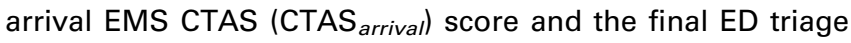
CTAS score $\left(\right.$ CTAS $\left._{\text {final }}\right)$ showed moderate agreement with kappa $=0.452(p<0.001,95 \% \mathrm{Cl} 0.437-0.466)$.

Conclusions: Interrater reliability of CTAS scoring between triage nurses and paramedics was moderate in this systemwide implementation study.

\section{RÉSUMÉ}

Objectifs: Le triage est un élément essentiel de l'évaluation des patients au service des urgences. Des systèmes efficaces de triage permettent de classer exactement les patients en ordre de priorité et aident à prévoir I'utilisation des ressources. L'ECTG est une échelle à cinq niveaux, validée et appliquée dans les services des urgences (SU) partout au Canada et ailleurs dans le monde. Les infirmiers de triage I'utilisent depuis longtemps dans les SU. Or, d'après des données d'observation, les ambulanciers paramédicaux pourraient appliquer I'ECTG en milieu préhospitalier, et ce, $d^{\prime}$ 'une manière fiable. II sera donc question ici de la première évaluation systémique de la fiabilité interévaluateurs, au regard de I'ECTG, entre ambulanciers paramédicaux et infirmiers de triage en pratique clinique.

Méthode: II y a eu extraction de variables provenant de bases de données d'hôpitaux et de SMU. Des fournisseurs de SMU ont déterminé, pour chacun des patients ( $n=14378$ ), le degré de gravité (DG) selon l'ECTG sur les lieux de l'événement, avant le transport dans un SU et à I'arrivée à I'hôpital. Le DG assigné par les SMU selon I'ECTG à l'arrivée à I'hôpital (ECTG ${ }_{\text {arrivée }}$ ) a été comparé au DG initial assigné par les infirmiers de triage selon I'ECTG (ECTG initial) ainsi qu'au DG définitif assigné par les infirmiers de triage

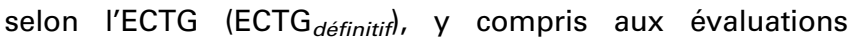
prépondérantes du personnel infirmier. La fiabilité interévaluateurs entre le DG indiqué au SU sur I'ECTG initial $_{\text {et le DG }}$ indiqué par les SMU sur I'ECTG arrivée a fait l'objet de comparaison; il en est allé de même pour le DG indiqué au SU sur I'ECTG définitif et le DG indiqué par les SMU sur I'ECTG arrivée. Enfin, les chercheurs ont évalué la proportion de patients pour lesquels la concordance d'évaluation était parfaite ou quasi parfaite.

Résultats: Le principal critère d'évaluation consistait en la fiabilité interévaluateurs (kappa $=0,437[p<0,001$; IC à $95 \%$ : $0,421-0,452])$, qui a révélé un degré moyen de concordance; le DG assigné par les SMU sur I'ECTG arrivée et le DG assigné

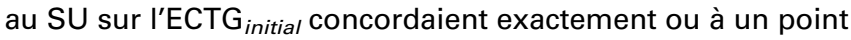
près dans $84,3 \%$ des cas. Quant au critère d'évaluation secondaire relatif à la fiabilité interévaluateurs, la comparaison entre le DG indiqué par les SMU sur l'ECTG arrivée

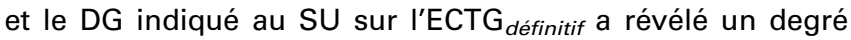
moyen de concordance (kappa $=0,452 ;[p<0,001 ; \mathrm{IC}$ à $95 \%$ : $0,437-0,466])$.

From the *Department of Emergency Medicine, †Section of Critical Care Medicine, and the \#Department of Community Health Sciences, University of Manitoba, Winnipeg, MB §Winnipeg Fire and Paramedic Service, Winnipeg Regional Health Authority, Winnipeg, MB; and the ףDDepartment of Emergency Medicine, University of Alberta, Edmonton, AB.

Correspondence to: Murdoch Leeies, T258-770 Bannatyne Ave., Winnipeg, MB R3EOW3; Email: umleeies@myumanitoba.ca 
Conclusions: Le degré de fiabilité interévaluateurs relatif à l'évaluation du DG selon I'ECTG entre infirmiers de triage et ambulanciers paramédicaux s'est révélé moyen dans cette étude systémique de mise en œuvre.
Keywords: Triage, Canadian Triage Acuity Scale, Emergency Medicine, Prehospital Medicine, Paramedic, Emergency Medical Services, Triage Nurse, Emergency Department Resource Utilization

\section{INTRODUCTION}

Triage is a fundamental component of prehospital and emergency department (ED) patient assessment. In health systems where ED overcrowding leads to delays in physician assessment of patients, effective triage systems accurately prioritize for seriously ill and high risk patients and help predict the scope of clinical services required. ${ }^{1,2}$ The value of electronic triage data as ED acuity and case-mix indicators in health services utilization research is evolving. ${ }^{2-7}$ The Canadian Triage and Acuity Scale (CTAS) is a five-level triage score that has been validated and widely implemented in EDs across Canada and internationally as a reliable and effective triage tool. ${ }^{3,8-16}$ CTAS scoring systems are available for both pediatric and adult populations. The CTAS consists of five triage levels combining severity of illness or risk with recommended fractile reponse times to medical assessment supported by a standardized patient presenting complaint list. ${ }^{17,18}$ Level 1 is considered most urgent and Level 5 least urgent. Traditionally CTAS has been applied by trained triage nurses in hospital EDs.

Current evidence supports high levels of interrater reliability of CTAS between physicians, nurses, and paramedics, but has been limited to non-clinical, paper-based cases $5,8,19$ or triage nurse agreement in an ED setting. ${ }^{10-12,14,15}$ Two prospective comparisons of interrater reliability between paramedics and triage nurses published in abstract form described fair $(\kappa w=0.37)$ to $\operatorname{good}(\kappa w=0.62)$ agreement. $^{21,22}$

\section{HYPOTHESIS}

Given similar training and supported by a clinical documentation tool, prehospital care providers can apply the CTAS with the same level of accuracy as triage nurses. The objective of this study is to prospectively evaluate CTAS interrater reliability between emergency medical services (EMS) providers and ED triage nurses with a system-wide implementation during routine clinical practice.
METHODS

\section{Study design/participants}

We conducted a prospective, observational cohort study of all patients $\geq 17$ years old transported to any ED in the Winnipeg Region by Winnipeg Fire and Paramedic Service (WFPS) EMS from July 1, 2014-December 31, 2014. The Winnipeg Regional Health Authority serves a metropolitan population of $>700,000$ citizens. An integrated network of seven EDs (one adult, one pediatric, five mixed) with an annual census of 200,000 visits, in combination with the WFPS, provide coordinated emergency medical care to the population. The WFPS operates an ALS off-line medical control paramedic service with the majority of ambulances staffed by a primary care paramedic (PCP) partnered with an advanced care paramedic (ACP). All patients assessed by both EMS and ED triage nurses were eligible for inclusion. There were no exclusion criteria. Ethics approval was obtained from the University of Manitoba Health Research Ethics Board for all aspects of this study. The Health Research Ethics Board waived the need for informed consent.

Data were extracted separately from the EMS electronic medical record (EMR) and the Emergency Department Information System (EDIS) databases into separate Microsoft Excel worksheets. The spreadsheets were then merged using the statistical software $\mathrm{R}$ (version 3.1.2) and RStudio (version 0.98); data linkage was accomplished using recorded EMS Run Number, Personal Health Information Number (PHIN), and date of birth, last name, and destination facility, which were recorded in both systems. All subsequent data analysis was performed in $\mathrm{R}$ with RStudio.

Prior to the onset of data collection, all EMS personnel in the WFPS were trained in application of the CTAS via a train-the-trainer model utilizing the same nationally standard CTAS education curriculum materials used to train WRHA ED triage nurses. Pre- and post- CTAS curriculum assessments were performed to evaluate skill acquisition as a matter of quality assurance. The WFPS follows an off-line model of medical control. During the 
study period in the prehospital setting, paramedics provided care according to their standard practice protocols with the addition of the CTAS assessment. EMS providers determined CTAS on-scene, CTAS prior to transport, and CTAS on arrival $\left(\mathrm{CTAS}_{\text {arrival }}\right)$ at hospital prior to their triage interaction for each patient. EMS CTAS scores were calculated with reference to a paperbased booklet and documented in an electronic medical records system on ruggedized laptops along with their standard documentation. Paramedics provided other clinical information to ED triage nurses according to current practice, but not their CTAS scores. Both nursing and paramedic CTAS scores were prospectively collected; EMS CTAS scores were not used clinically.

CTAS scores for ED triage nurses were calculated and recorded electronically as part of routine clinical practice. Initial ED CTAS scores $\left(\mathrm{CTAS}_{\text {initial }}\right)$ are generated in EDIS using computerized clinical decision support by the triage nurse. Nurses can then either accept the computer-assisted CTAS score, or override the CTAS score $\left(\mathrm{CTAS}_{\text {final }}\right)$ in order to better match their impression of patient acuity. EMS providers do not have the ability to override the CTAS score. Both the $\mathrm{CTAS}_{\text {initial }}$ and $\mathrm{CTAS}_{\text {final }}$ scores were analyzed.

All ED triage nurses and EMS providers were blinded to each others' scores, which were maintained in separate electronic systems. Medical Supervisors (WFPS paramedics with an enhanced scope of practice) reinforced this blinding throughout the study period.

\section{Outcomes/variables}

Our variables of interest were the final CTAS score calculated by EMS immediately prior to their triage interaction in the ED $\left(\mathrm{CTAS}_{\text {arrival }}\right)$ compared to both the baseline CTAS score calculated by triage nurses $\left(\mathrm{CTAS}_{\text {initial }}\right)$ and the final score including nursing overrides $\left(\right.$ CTAS $\left._{\text {final }}\right)$.

Our primary outcome was interrater reliability for triage nurse baseline CTAS $_{\text {initial }}$ and EMS CTAS arrival $_{\text {. }}$ scores. Secondary outcomes included interrater reliability on ED triage nurse CTAS $_{\text {final }}$ CTAS and EMS CTAS $_{\text {arrival, }}$ as well as proportion of patient encounters with perfect or near-perfect agreement.

\section{Secondary analyses}

We compared the distribution of CTAS scores between nursing and EMS to identify trends in scoring.
Subgroup analysis of interrater reliability between nursing and EMS at tertiary versus community ED sites was performed. Differences in admission rates between higher acuity (CTAS 1-3) and lower acuity (CTAS 4-5) patients, as assigned by nursing and EMS, were assessed.

\section{Statistical analysis}

Interrater reliability for triage nurse CTAS scores and

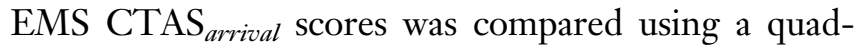
ratic weighted kappa ( $\mathrm{\kappa w})$ statistic for primary and secondary outcomes as well as subgroup analyses. Using the Wilcoxon Signed Rank test, CTAS distributions between nursing and EMS were examined through comparison of the proportion of scores in each category to identify statistically significant differences. The proportion of patients admitted in higher acuity (CTAS 1-3) and lower acuity (CTAS 4-5) groups, as ranked by triage nursing and EMS, were compared using the Chi Squared tests, and average length of stay for these two groups were compared using standard t-tests.

Sample size for multicategory weighted kappa was estimated as at least 50 patients per category. ${ }^{20}$

\section{RESULTS}

From July-December 2014, 14,378 consecutive adult patient encounters in the Winnipeg Region were evaluated. Patients were 17-105 years old and 55\% female. Case-mix was representative of the ED patient population utilizing EMS transport. There were 17,328 eligible records in the EMS dataset, and 15,876 records in the EDIS dataset. The primary reason for the lower number of eligible records from EDIS was a failure on the part of triage nurses to universally record an EMS run number on the triage note. Overall, a total of 14,378 records were positively matched between the two sources.

Unweighted (k) and both linear- (kWL) and quadratic-weighted kappa (kWQ) were calculated. Kappa agreement was defined a priori as excellent $(\mathrm{k}>0.8)$, good $(0.6<\mathrm{k}<0.8)$, moderate $(0.4<\mathrm{k}<0.6)$, fair $(0.2<\mathrm{k}<0.4)$ or poor $(\mathrm{k}<0.2) .{ }^{21}$ Our primary outcome, interrater reliability between EMS CTAS $_{\text {arrival }}$ and ED CTAS initial $_{\text {scores (the CTAS score }}$ prior to overrides), indicated moderate agreement $[\kappa w=0.437(p<0.001,95 \%$ CI $0.421-0.452)]$. EMS CTAS $_{\text {arrival }}$ and ED CTAS initial $_{\text {scores had an exact or }}$ 
Prehospital Application of CTAS by EMS (PACE)

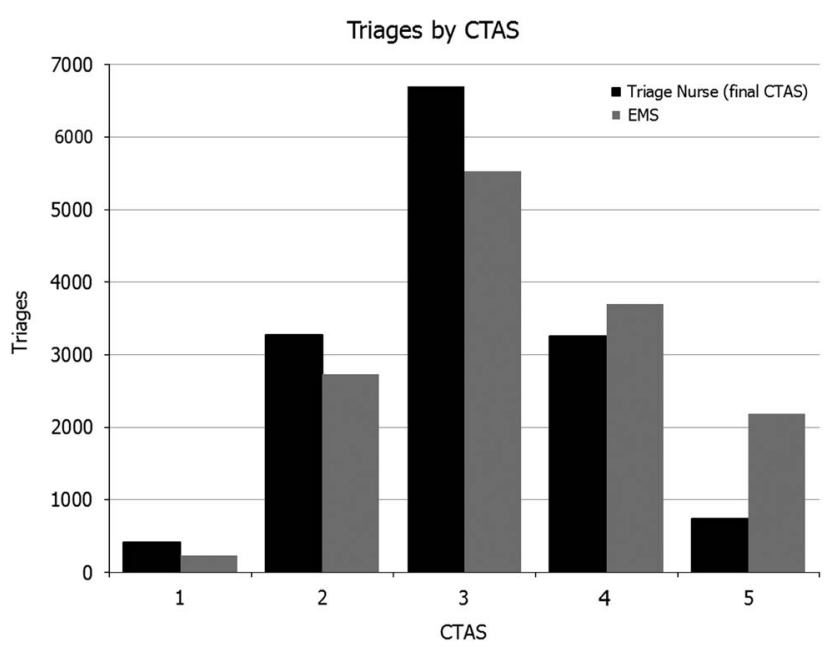

Figure 1. Frequency distributions of CTAS scores

within one point match $84.3 \%$ of the time. The secondary interrater reliability outcome between EMS CTAS $_{\text {arrival }}$ and ED CTAS final $_{\text {score (including nurse }}$ overrides) also showed moderate agreement $[\mathrm{kw}=$ $0.452(p<0.001,95 \%$ CI $0.437-0.466)]$ and an exact or within one point match $86.5 \%$ of the time.

The distribution of CTAS scores is demonstrated in Figure 1. Table 1 summarizes the proportions of matched CTAS scores between EMS providers and ED triage nurses.

It was observed that, when compared to the triage nurses, EMS tended to score patients equal or lower for CTAS 1, 2, and 3 patients, but tended to score equal or higher for CTAS 4 and 5 patients. This observed difference was examined using the Wilcoxon Signed Rank test on these two dependent subsets, which identified a significant difference not equal to zero $(p<0.001)$.

Assessed using the Chi-Squared test, the difference in the proportion of admissions for EMS-coded high-acuity (CTAS 1-3) patients (0.284) versus triage nurse-coded high-acuity patients $(0.274)$ was not statistically significant $(p=0.102,95 \%$ CI $-0.00214-0.09236)$. The difference in proportion of admissions for low-acuity patients (CTAS $4-5)$, however, was statistically significant ( 0.173 vs. 0.148 , $p<0.05,95 \%$ CI 0.0102-0.0396).

A subgroup analysis evaluated our primary interrater reliability outcome at tertiary university-affiliated sites versus community sites. There was a non-significant trend toward better agreement between paramedic CTAS $_{\text {arrival }}$ and triage nurse CTAS $_{\text {final }}$ evaluations in tertiary sites $[\mathrm{kw}=0.469(95 \% \mathrm{CI} 0.447-0.491)]$ versus $[\mathrm{kw}=0.439(95 \%$ CI $0.421-0.457)]$. There was no

\begin{tabular}{|c|c|c|c|c|c|}
\hline \multirow[b]{2}{*}{ Triage Nurse CTAS } & \multicolumn{2}{|c|}{ EMS CTAS } & \multirow[b]{2}{*}{3} & \multirow[b]{2}{*}{4} & \multirow[b]{2}{*}{5} \\
\hline & 1 & 2 & & & \\
\hline 1 & 0.426 & 0.475 & 0.073 & 0.022 & 0.005 \\
\hline 2 & 0.012 & 0.505 & 0.293 & 0.116 & 0.074 \\
\hline 3 & 0.003 & 0.104 & 0.5 & 0.257 & 0.136 \\
\hline 4 & 0 & 0.049 & 0.32 & 0.421 & 0.21 \\
\hline 5 & 0 & 0.034 & 0.206 & 0.294 & 0.466 \\
\hline
\end{tabular}

statistically significant difference in proportion of patients admitted to hospital categorized by paramedic versus triage nurse CTAS score when CTAS was dichotomized into high- (CTAS 1-3) and low- (CTAS 4-5) acuity groups.

\section{DISCUSSION}

There is a growing body of literature on the inter- and intra-rater reliability of the CTAS between health care providers. Beveridge et al. published the first study showing good concordance rates between physicians and nurses for the application of the CTAS to written case reports $(\kappa \mathrm{w}=0.8) .{ }^{1,8}$ Fernandes et al. reproduced a high level of agreement $(\kappa w=0.79)$ between community and tertiary ED triage nurse scores on paper-based cases. ${ }^{19}$ Grafstein et al. showed that paired ED triage nurses observing a single clinical interaction could apply CTAS with similar levels of agreement in clinical practice $(\mathrm{\kappa w}=0.75) .{ }^{15}$ Dong et al. published a series of papers examining the interrater reliability of CTAS using eTRIAGE (an electronic CTAS decision support tool) and blinded triage nurse assessments, and demonstrated improved accuracy using electronic decision support compared to memory- or paper-based methods, ${ }^{11}$ with good agreement between nursing scores $(\kappa w=0.66)^{10}$ and improvement in agreement with ongoing CTAS training. ${ }^{12}$

Manos et al. also demonstrated a high level of agreement between physicians and nurses when applying CTAS to written cases and expanded their scope to include BLS and ALS paramedics, who also showed good concordance $(\mathrm{\kappa w}=0.77){ }^{5}$ The generalizability of these findings to clinical practice is limited by the use of paper-based cases in artificial circumstances, or calculation of CTAS scores based on observation but not participation in clinical interactions. It has been suggested that visual or non-verbal cues from individual 
patients in vivo, along with environmental stimuli such as departmental crowding, have significant impact on triage processes. ${ }^{22}$ As such, the interrater reliability of the CTAS would be expected to vary more in clinical practice than in paper-based scenarios. Prospective evaluation of prehospital CTAS interrater reliability in practice has been limited to two studies presented as abstracts: Murray and Bondy described good interrater reliability of CTAS assessments between EMS providers and triage nurses $(\kappa w=0.61)$ in clinical practice, although significant variability was noted between centers (quadratic weighted kappas ranged from $\mathrm{kw}=$ 0.7 to $\mathrm{Kw}=0.47) ;{ }^{23}$ Smith et al. found fair agreement $(\kappa \mathrm{w}=0.37)$ between CTAS scores assigned by EMS providers and triage nurses in a prospective study of 1,131 EMS transports, although these findings may be limited by the fact that the EMS providers relied on memory, while the triage nurses used an EDIS with programmed CTAS clinical decision support. ${ }^{24}$

Previous studies of paramedic acuity assessments in the field using non-CTAS scales or clinical judgement have also yielded mixed results. In a prospective survey with linked medical record review, Hauswald demonstrated moderate-to-fair agreement between paramedics and physicians when evaluating whether patients required ambulance transport and medical attention in the $\mathrm{ED}(\kappa \mathrm{w}=0.47$ and $\kappa \mathrm{w}=0.32$, respectively). ${ }^{25}$ Silvestri et al. had similar results, finding that paramedic assessment was $81 \%$ sensitive but only $34 \%$ specific for predicting requirement of ED care. ${ }^{26}$

Our study has some limitations that warrant consideration. It has been previously noted that ED conditions, such as overcrowding and resource-intensive cases in the resuscitiation area, may influence triage nurse CTAS assignment based on their awareness of flow realities. If done indiscriminantly, this is referred to as triage drift (towards mean scores), to be contrasted by experienced nurses who sometimes use judgment to appropriately override calculated CTAS score and prioritization based on patient acuity. ${ }^{10,27}$ EMS providers need only assign a CTAS score to the individual under their care, irrespective of the state of the ED they are presenting to. Future research should include consideration of the impact of system factors on CTAS interrater reliability between EMS providers and triage nurses. While EMS and ED CTAS scores were entered and housed in independent electronic systems and maintenance of blinding was routinely reinforced, it was not possible to monitor every triage interaction and confirm blinding was maintained. There were missing data due to incomplete documentation by ED nurses $(1,452 / 17,328$ or $8.4 \%$ of potential records could not be reliably matched), which could potentially represent an underlying source of selection bias not identified.

We have demonstrated that EMS providers can assign CTAS scores with moderate interrater reliability when compared with ED triage nurses. Our results support that EMS providers can be trained and apply CTAS in their routine practice in an off-line medical control system with a moderate level of agreement compared to ED triage nurses. It is important to recognize that EMS providers are applying the CTAS to a single patient and repeating that assessment on several occasions, looking for any acuity change. They are not comparing their patient to any other, or making decisions about the level of priority. EMS providers may complete a more comprehensive assessment than the triage nurse, who must manage, triage, and prioritize all patients presenting to the triage desk and being held in the waiting room, while balancing the availability of staff and treatment spaces in the ED. It may be unreasonable to expect perfect agreement between these providers; however, one intuitive benefit in standardized definitions and descriptors of patient acuity is the potential for enhanced patient care and meaningful comparisons of data.

\section{CONCLUSIONS}

EMS providers can assign CTAS scores during routine clinical practice with moderate interrater reliability as compared to ED triage nurses. The region-wide nature of our study supports the generalizability of these results to other systems. Further research is needed to define the role of CTAS in EMS systems where alternate levels of care and/or delayed- or non-transport processes are incorporated. Future studies should also evaluate the impact of CTAS acuity change from the scene to the ED to determine whether this is a predictor of a higher risk patient than those patients who remain stable from on-scene to $\mathrm{ED}$, and to characterize the impact of prehospital interventions on patient acuity.

Acknowledgements: The authors would like to thank Lori Mitchell, PhD, Researcher with the Winnipeg Regional Health Authority, for her statistical input.

Competing Interests: None declared. 


\section{REFERENCES}

1. Beveridge R. CAEP issues. The Canadian Triage and Acuity Scale: a new and critical element in health care reform. Canadian Association of Emergency Physicians. 7 Emerg Med 1998;16(3):507-11.

2. Innes G, Stenstrom R, Grafstein E, et al. Prospective time study derivation of emergency physician workload predictors. CFEM 2005;7(5):299-308.

3. Jiménez JG, Murray MJ, Beveridge R, et al. Implementation of the Canadian Emergency Department Triage and Acuity Scale (CTAS) in the Principality of Andorra: Can triage parameters serve as emergency department quality indicators? CFEM 2003;5(5):315-22.

4. Dreyer JF, McLeod SL, Anderson CK, et al. Physician workload and the Canadian emergency department triage and acuity scale: The predictors of workload in the emergency room (POWER) study. C7EM 2009;11(4):321-9.

5. Manos D, Petrie DA, Beveridge RC, et al. Inter-observer agreement using the Canadian Emergency Department Triage and Acuity Scale. C7EM 2002;4(1):16-22.

6. Lin D, Worster A. Predictors of admission to hospital of patients triaged as nonurgent using the Canadian Triage and Acuity Scale. C7EM 2013;15(6):353-8, doi:10.2310/8000. 2013.130842 .

7. Dong SL, Bullard MJ, Meurer DP, et al. Predictive Validity of a Computerized Emergency Triage Tool. Acad Emerg Med 2007;14(1):16-21, doi:10.1197/j.aem.2006.08.021.

8. Beveridge R, Ducharme J, Janes L, et al. Reliability of the Canadian Emergency Department Triage and Acuity Scale: interrater agreement. Ann Emerg Med 1999;34(2):155-9, doi:10.1016/S0196-0644(99)70223-4.

9. Elkum NB, Barrett C, Al-Omran H. Canadian Emergency Department Triage and Acuity Scale: implementation in a tertiary care center in Saudi Arabia. BMC Emerg Med 2011;11:3, doi:10.1186/1471-227X-11-3.

10. Dong SL, Bullard MJ, Meurer DP, et al. Reliability of computerized emergency triage. Acad Emerg Med 2006; 13(3):269-75, doi:10.1197/j.aem.2005.10.014.

11. Dong SL, Bullard MJ, Meurer DP, et al. Emergency triage: comparing a novel computer triage program with standard triage. Acad Emerg Med 2005;12(6):502-7, doi:10.1197/j.aem.2005.01.005.

12. Dong SL, Bullard MJ, Meurer DP, et al. The effect of training on nurse agreement using an electronic triage system. CFEM 2007;9(4):260-6.

13. Ng C, Hsu K, Kuan J, et al. Comparison between Canadian Triage and Acuity Scale and Taiwan Triage System in emergency departments. 7 Formos Med Assoc 2010; 109(11):828-37.
14. Ng CJ, Yen ZS, Tsai JC, et al. Validation of the Taiwan triage and acuity scale: a new computerised five-level triage system. Emerg Med $f$ 2011;28(12):1026-31, doi:10.1136/emj.2010.094185.

15. Grafstein E, Innes $G, W$ estman J, et al. Inter-rater reliability of a computerized presenting-complaint-linked triage system in an urban emergency department. CFEM 2003; 5(5):323-9.

16. Worster A, Gilboy N, Fernandes CM, et al. Assessment of inter-observer reliability of two five-level triage and acuity scales: a randomized controlled trial. CFEM 2004;6(4): 240-5.

17. Murray M, Bullard M, Grafstein E. Revisions to the Canadian Emergency Department Triage and Acuity Scale implementation guidelines. CFEM 2004;6(6):421-7, doi: $10.2310 / 8000.2014 .012014$.

18. Bullard MJ, Unger B, Spence J, et al. Revisions to the Canadian Emergency Department Triage and Acuity Scale (CTAS) adult guidelines. C7EM 2008;10(2):136-51.

19. Fernandes CMB, McLeod S, Krause J, et al. Reliability of the Canadian triage and Acuity Scale: interrater and intrarater agreement from a community and an academic emergency department. CFEM 2013;15(4):227-32, doi:10.2310/8000.2013.130943.

20. Soeken K, Prescott P. Issues in the use of kappa to estimate reliability. Med Care 1986;24(8):733-41.

21. Kramer M, Feinstein A. Clinical biostatistics. LIV. The biostatistics of concordance. Clin Pharmacol Ther 1981; 29(1):111-23.

22. Dallaire C, Poitras J, Aubin K, et al. Interrater agreement of Canadian Emergency Department Triage and Acuity scale scores assigned by base hospital and emergency department nurses. CFEM 2010;12(1):45-9.

23. Murray MJ, Bondy S. The reliability of the Canadian Emergency Department Triage and Acuity Scale in the prehospital setting: interrater agreement between paramedics and nurses. CFEM 2002;4(2):128.

24. Smith K, Lobay K, Bullard MJ. Implementation and reliability of the Prehospital Canadian Triage Acuity Score (Pre-CTAS). CFEM 2014;16(S1):S26.

25. Hauswald M. Can paramedics safely decide which patients do not need ambulance transport or Emergency Department care? Prehosp Emerg Care 2002;6(4):383-6.

26. Silvestri S, Rothrock SG, Kennedy D, et al. Can paramedics accurately identify patients who do not require Emergency Department Care? Prehosp Emerg Care 2002;6(4): 387-90.

27. Bjørn P, Rødje K. Triage Drift: A Workplace Study in a Pediatric Emergency Department. Comput Support Coop Work 2008;17(4):395-419, doi:10.1007/s10606-008-9079-2. 